\title{
Study on the Inheritance and Development of Baoshan Han Culture with "Tiandi Tablet" as an Example Liqiong Tai
}

\author{
School of Humanities, Baoshan university, Baoshan, Yunnan, 678000, China
}

Keywords: "Tiandi Tablet", Baoshan, Han Culture, Inheritance and development.

\begin{abstract}
The folk custom of "Tiandi tablet" has been extinct or disappearing in many towns across the country. In the rural areas of Shidian, Changning, Longling and Tengchong in the Baoshan area, sacred and solemn Tiandi tablets can be seen everywhere. "Tiandi tablet" beliefs are spread across the rural-urban finge zones and rural areas, and even ethnic minority families are no exception. This is the most powerful and characteristic external manifestation of the inheritance and development of Baoshan Han culture.
\end{abstract}

\section{Introduction}

"Tiandi tablet", also known as "family", "family card", is a spiritual tablet set in the central scroll of the main house. It is a sacred place dedicated to the gods, the land, the kitchen god, and the past relatives. "Tiandi Tablet" generally consists of three parts: from the right to the left, there is the "Zoushan Hall", dedicated to the land god and the kitchen god, "Five Fortune Hall", dedicated to heaven, earth, king, pro, teacher, "Liufang Hall", dedicated to the past relatives. In addition to these three parts, some places have added "Treasure Hall" to worship "Nangong Tianzi Profit Seven-Treasure God", and have taken out "Jiqing Hall" from "Zoushan Hall" dedicated to " Zhonggong Land God Mrs. Zhuangqing". The entire background of the Tiandi tablet is red, and the words are yellow, sacred and solemn.

\section{The writing and meaning of Chinese characters in classical Chinese}

One of the important characteristics of Han culture or Chinese culture is the writing of Chinese characters and the thinking through Chinese characters. The basis for the production of Chinese characters is the pictogram. The ancients directly depicted the things they saw through the images they saw, and directly create words according to the image. Therefore, there are many symbolic meanings and profound meanings in the written Chinese characters in classical Chinese.

In the Baoshan area, "Tiandi tablet" must be hand-written by the local folk priests and gentlemen hired by most of the villages. During the writing process, the traditional Chinese characters "Tian, Di, Jun, Qin, Shi and Wei" are written in a special strict way, with stipulations that must not be overstepped, and all strokes that imply a profound cultural significance.

For example, the word "Tian" requires "man does not take the place of heaven", that is, the left stroke of the character word Ren can't write from the very top but to keep a certain distance, suggesting that the sky is supreme and the origin of all things, and one must obey the dominant heaven and do more good deeds to be protected by God; the word "Di" requires "the land does not leave the earth", meaning that the vertical stroke of the word Tu must be connected with the horizontal one below, suggesting that the earth raises all things, and people cannot leave the land and must base ourselves on the land to survive; the word "Jun" requires "Jun is not to leave the mouth", which means that the word Kou below must be sealed, meaning that the king's words carry weight and the mouth cannot be opened carelessly; "Families do not close eyes" means that the word "Mu" in the traditional word "Qin" cannot be sealed, meaning the family members do not die and live a long and happy life; the word "She" requires "teacher not to drop the turban", meaning that the traditional 
character "Shi" does not need the short stroke on the left side, suggesting that the teacher should not be left aside, and people should always learn from the teacher; the word "Wei" requires "people do not leave the position", meaning that the word "Li" on the right must have its horizontal stroke connected to the "Ren" side, suggesting that people must recognize where they are, stick to their own post and do not offside.

For the above six words, the writing norms and writing rules of classical Chinese, embody the deep cultural connotation in the form of "shape". In the calligraphy structure of Tiandi Tablet, it not only reflects the characteristics of Chinese classical Chinese, but also implies profound meanings in each stroke, which retains the characteristics of the original "shape" of Chinese characters, so that the cultural characteristics of Chinese characters continue.

\section{The embodiment of the traditional culture of Yin and Yang Five Elements}

The five elements of yin and yang, namely gold, wood, water, fire and earth, are typical aspects of Chinese traditional culture. The five elements promote and restrict each other. The five elements of yin and yang unify the orientation of the space and the time series, forming a space-time synthesis, which can connect or interpret everything in the world in the two poles of time and space. For example, the five elements can be equipped with five parties, and can be equipped with five sounds, etc., to connect everything in the world into a large and transformed network, which runs through many aspects of Chinese culture.

"Tiandi tablet", for the ancestral tablets in the third part of the "family hall", "Liufang Hall", is generally called the ancestral tablets. The full name is: " $\mathrm{x}$ sound $\mathrm{xx}$ county $\mathrm{x}$ ancestor incense position". Taking Yang as an example, it is: "Shang Sound Hongnong County Yang's ancestral incense position." It is a tablet dedicated to the souls of the ancestors.

The words "sound" and "county" on the ancestors have their origins. The sound is the five-tone in ancient times. In order to appreciate the song and dance art of the palace maids, the emperors arranged the instruments according to the five elements, wood, gold, fire, water, and soil, in five directions: east, west, south, north and center. The five tones Jiao, Shang, Zhi, Yu, and Gong are used to determine the five directions. The direction where the earliest ancestors of each family name came from is the tone of that position. For the county, China began to set up counties from the Qin Dynasty, which has been used till the Tang Dynasty. Later, the name changed, which is equivalent to the current county-level local administrative units. The ancestral tablet carries the historical memory of the Baoshan people's ancestral source, and reflects the root-seeking consciousness and the Central Plains complex of the Baoshan people.

\section{The construction of the social structure of the home, family and home country}

The home, family, and home country in the Han culture emphasize social order. In such ethical principles and hierarchical order, one requires "internal and external differences" and the other requires "up and down order." Under this Confucian ethical concept, most Chinese believe that the country is a magnified home, and the home is a country that is shrinking, orderly, internal and external.

In the farmer's house in Baoshan area, the house is almost the same structure: the house is composed of three rooms, the left wing of the house is the kitchen, there is a fire pit, the room for cooking and eating; the right wing is the main bedroom; as the living room, the middle house is the main house where the "Tiandi Tablet" is enshrined.

The main house of the traditional house is a space for worship. Some scholars describe the "main house" of traditional Chinese dwellings: "For most outside observers of the 19th and 20th centuries, Chinese houses seem to be a family temple first," the altar is dedicated to the main building. In the room, in the heart of the entire house - the facade is facing the courtyard. The whole house is built around the house, and the orientation and layout are the focus. The number of the house must be singular, so the ancestral altar is in the right place. The pole of the whole house is in the center of 
symmetry, thus ensuring its dominance and center position. Around the main hall, there are left and right ear rooms next to each other, the houses are symmetrically arranged. The general parents live in the main house, the children are arranged in rooms according to certain order, and the guests live upstairs. There is order about up and down and difference between inside and outside.

In such a space for housing construction, people have built a home, family, and home country through the ritual of sacrifice. There are two main rituals: one is a family ritual, which is a ritual of ancestor organized by the family. This is the most popular and simplest ritual of ancestor worship. For ordinary people, including ethnic minority families, to the home of the "Tian, Di, Jun, Qin, Shi and Wei" must be given sacrifices by male elders before every meal. Important events and festival sacrificial ceremonies are grand and complex, and the daily sacrifice ceremony is relatively simple, just for meals. Many families must burn incense on the first, fifteen or two days of each month. Whether it is a daily diet or a house, the red and white weddings and important festivals must be sacrificed to the "family". Therefore, the ancestor has the source of drinking water, carefully pursues the distance, repays the benevolent, and stresses the cultural behavior of filial piety. The second is the family sacrifice. It is in the ancestral hall to worship the ancestors. There are family sacrifices, family sacrifices, and state-owned sacrifices. All families in Baoshan Tengchong have built ancestral halls in the village. Taking Heshun Township as an example, in the village where the radius is less than ten miles and the residents are not more than 1,000 households, there are eight large halls of inch, Liu, Li, Yin, Jia, Zhang, Yi and Yang. These main halls of the Ancestral Hall were built on a high base. There are three rooms in the middle, and there is a platform in the middle. The temple is dedicated to the ancestors and their ancestors. Every year during the Ching Ming Festival, each clan will hold a grand ritual ceremony in the ancestral hall. People from all over the country and even overseas will gather together to worship the ancestors.

There is a family above an individual, a nation on the other, a country on the national level. Holding an ancestor activity in memory of the family's home country is the feeling of home and country. The "family hall" and "ancestral hall" are both equipped with ancestral tablets. Around the "worship of ancestors" as the center of the ceremonial activities, the home, family, and home country are different from each other, and the social structure is up and down.

\section{The world of belief in the "Three Religions in One"}

Confucianism, Buddhism, and Taoism are the mainstay of Chinese traditional culture and the foundation of Chinese culture. In the "Tiandi Tablet" belief that is widely existed in Baoshan area, the "three sacrifices" of Confucianism "the sacrifice of heaven and earth, the sacrifice of ancestors, and the sacrifice of sages" were practiced. The scorpion once said that "there are three rituals": "The heaven and earth, the birth of the ancestors; the ancestors, the class of the genius; the princes, the rule of the ruins....the rites of the heavens, the next thing, the ancestors and the ancestors The monarch is also the third of the ceremony."Tian, Di, Jun, Qin and Shi" represent the world, the kingdom, the parents, the teacher and the position of oneself. It also highlights the concepts of "the gods are humble", "the monarchical authority", "the family and the state", "the combination of the monarch and the teacher" and "loyalty to the duty", which condenses many things of Chinese traditional culture. It shows the worship of heaven and earth, loyalty to the motherland, filial piety, respect for the teacher, and dedication to the excellent Chinese traditional culture; it expresses the world outlook and the ethical outlook on life and morality of the world.

Taoism believes in folk custom, is a multi-god belief, following the ancient Chinese beliefs about the sun, the moon, the stars, the rivers, the mountains, and the ancestors of the dead, forming a complex god system of gods, mantles and ghosts. One of the components of "Tiandi Tablet" is "Playing Good Hall", and its tablet is written like this: "Nine days of East Kitchen Division's life stove Wangfujun, the town house Zhonggong Landford is the god." Zaojun, the land two gods are Folk custom, Taoism is God. Zaojun is also known as "the stove god". The kitchen god found that someone did a bad thing and reported it to the Jade Emperor. At the same time, the stove is also responsible for monitoring the people. Therefore, the people are respectful and fearful of the stove, 
and this special "Evil Reporting" God respects it as "Good Reporting Stove God". The land god is the lowest level of the gods in the gods, only in charge of a section of the ground, but since ancient times the people have been interdependent with the land, the land is the source of people's food and clothing, the basis of survival. Therefore, people also worship the land as a god, and the incense of generations is endless.

The three major structures of "Tiandi Tablet" reflect people's multi-god worship of the three-dimensional pattern of the gods, the earth, and the ghosts. According to the thinking habits of Chinese traditional culture, it is believed that the three most basic elements that constitute the universe are heaven, earth, and people (also known as "three talents"). "Tiandi Tablet" is the concrete manifestation of people's concept of worship of gods, worship of earth gods, and worship of ghosts. The setting of Tiandi Tablet fully embodies the cultural concept of the Han nationality, is the place where people's spiritual sustenance and the soul settle, and is also the basis for the legality and rationality of many ethics in Chinese traditional society. they support the building of the spirit of Chinese traditional folk society like pillar stones.

In addition, Baoshan is also a multi-ethnic area where ethnic minorities have multiple beliefs. For example, the Bai people believe in Buddhism, Taoism, the Lord's religion and Confucianism. This phenomenon is manifested in the fact that the Bai people have Buddhist temples in the family, offering Buddhas, the ancestral tablets, the main gods and the heavens and the earth. The monarch's position is enshrined in the temple. Most of the Bai people worship the Buddha and respect the ancestors, worshiping the goddess of Guanyin and Buddha, and worshipping the Jade Emperor of Taoism, paying attention to the worship of the gods and the lessons of the Tao, and worshipping the Lord and the Nine altars. There have been many phenomena in which religions coexist harmoniously. The belief that the "three religions are united" is not only among the ethnic minorities but also among the Han people.

The Confucianism, Buddhism and Taoism beliefs combine the heavens and the earth, the sun and the moon, the four o'clock, and the gods and ghosts. Focusing on the ancestor worship that advocates "benevolence and filial piety" as the core, through the worship of ancestors, Buddhist gods, ancient saints and Taoist folk gods, it reflects the long-standing spiritual sustenance and filial piety of Chinese culture. The combination of the three religions, the benevolence of the benevolent people, the reverence of the people, the generalization of the people, the construction of the ideal spiritual home of the Chinese nation, its ethical standards and spiritual pillars as the Chinese people will continue to be passed down.

\section{National identity of the "root" consciousness}

The Han culture of the Central Plains region has entered the current Baoshan area since the Western Han Dynasty and was firmly preserved in Baoshan. The Han people spread Han culture in Baoshan through immigration, shackles, squatting, squatting, and education. It can be said that most of the Han ancestors of the Baoshan people originated from the vast Central Plains region. Today's Baoshan people belong to the descendants of the Central Plains immigrant society.

The Han immigrants came to the Baoshan area in the west of the country from their original place of residence. Although they were far away from the Central Plains and away from their homeland, they never forgot the core of their own culture. They cultivated genealogy, worshipped the "Tiandi tablet", ancestral tablets, and built the ancestral temple. Emphasize their common clan and blood. The identification of ancestors and blood relations is still rooted in the deep consciousness of the people in the foreign land, and is integrated into the daily activities of the people.

It is precisely because of this "root" consciousness that the memory of the ancestors and the identification of the ancestors formed a centripetal force toward the country. It also brings the Han culture brought by them to a dominant position in the development of Baoshan culture, and has a deeper impact on the influence and transformation of Baoshan's various national cultures. Under the inspiration of this mainstream culture, a huge cohesive force was issued in the west Fujian, firmly safeguarding the unity of the Laos and the stability of the frontiers. 


\section{Summary}

Since modern times, there has been the overthrowing of the monarchy, the opposition of the old culture and the promotion of new cultures. China has to go beyond the traditional culture and seek new. Thus the traditional culture is facing a crisis. The so-called "three norms and five permanents" and the moral values of the benevolence and righteousness have become inappropriate compared to the modern values of freedom, democracy and human rights in the West. In the face of the Western and Eastern powers, the cultural confidence and calmness of the Chinese people in the past have been difficult to see, but in an anxiety and nervous state of mind. This change shows that Chinese culture especially the Han Chinese culture - is already in an era that needs to be re-recognized, re-understood and renewed. Isn't cultural self-confidence just asking us to re-examine our traditional culture?

\section{References}

[1] Liu Wei. Analysis of the Spatial Structure and Significance of the Traditional Houses of the Bai People in Dali under the Shield of Ancestors. Journal of Guizhou University for Nationalities. 2015.2.

[2] Wang Xianqian. The collection of Xuncius. Zhonghua Book Company. 1996.

[3] Ma Yong. Dai Yanzhi. On the Historical Memory and Ethnic Identity of the Han Immigrants in Tengchong in the Ming and Qing Dynasties. Journal of Yunnan University for Nationalities. 2015.5.

[4] Ge Zhaoguang. What is the "Chinese" culture. Decision-making Exploration. 2015.9. 